\title{
Linguistic Landscape as a Means of Reinforcing Character Education for Senior High School Students
}

\author{
Eti Setiawati ${ }^{1 *}$, Esti Junining ${ }^{2}$
}

\author{
${ }^{1,2}$ FIB Universitas Brawijaya \\ * Corresponding author. Email: ety64@ub.ac.id
}

\begin{abstract}
Language study in the public area known as Linguistic Landscape (LL) is a modern sociolinguistic study that consists of various branches. It includes language implicitly shown in traffic signs, advertisement boards, names of streets, names of areas, name of shops, public directions, and boards of notifications at schools. This study is intended to describe the following: 1) values of character education represented outside the classrooms, and 2) character reinforcement for the students. This is a descriptive qualitative study, in which the data are collected by observation, document analysis and file notes. Data analysis procedures include data reduction, interpretation analysis, clarifications, and summarizing. The result shows that there are eight values of character education represented by linguistics landscape outside the classrooms namely 1) environment maintenance, 2) prevention of juvenile delinquency, 3) health, 4) discipline, 5) motivation, 6) behaviours, 7) religious beliefs, and 8) nationalism. Regarding the character reinforcement for the students outside the classroom, the LL can reinforce the students' moral values in terms of maintaining the environment, preventing juvenile delinquencies, cultivating disciplines, and motivating religious beliefs and nationalism.
\end{abstract}

Keywords: linguistic landscape, a means of reinforcing, character education, Senior High School Students

\section{INTRODUCTION}

The increasing and varied use of language in public spaces such as on signboards, advertisements, appeals, and banners indirectly benefits knowledge and even it has an impact on changing the mindset and behaviour of the people who read it. As mentioned by Cenoz \& Gorter, [1]; Spolsky,[2]; Taylor-Leech, [5] that several countries or cities have also issued regulations regarding language policies used in the public spaces. Regulations related to Linguistic Landscape (LL) simultaneously regulate language policies in the field of education, media, socio-economic life, and many more. Several studies also show there is a strong influence between 3 language policies and language use in public spaces.

The use of language in public spaces is not only found on street signboards, business name boards. It is also found on signboards inside and outside classrooms at schools. The language content on boards of notifications at schools is different from the language content found on street signboards, business entity name boards, and nameplates in public spaces of other agencies. The boards of notifications at schools environment will surely be related to the guidance and development of student behaviour at the school so that students become superior individuals, as mandated in the 1945 Constitution article 31 paragraph 3 , "To educate the life of the nation and develop Indonesians as a whole, namely humans who believe and fear God Almighty and have a noble character, have knowledge and skills, physical and spiritual health, a solid and independent personality and a sense of social and national responsibility."To find out the values contained in the use of language in public spaces in schools that are written on the boards of notifications, the researcher uses the concept of character education from the Department of Education and Culture of the Republic of Indonesia, which classifies the values of character education into 18, namely religious, honest, tolerance, discipline, hard work, creative, independent, democratic, curiosity, the spirit of nationality, love for the homeland, respect for 
achievement, friendly/communicative, love peace, love to read, care for the environment, care about social, and responsibility.

In addition, related to the concept of LL, the researcher uses the opinion of Landry and Bourhis [3] who stated that LL has two functions, namely informational and symbolic functions. In the informational function, the meaning of the marker distinguishes the geographical area of the population that gives the language of the place's nameplate or the language functions as a marker of the area of the community that speaks it and distinguishes it from other populations' areas with different languages. In symbolic function, the presence or absence of a group's language on the board has an impact on the feeling of belonging to that group. The symbolic function is also closely related to the representation of ethnic identity. Blommaert [4] refers to space as human social interaction and carrying out a series of cultures. The interaction space can be assessed as a form of complex action/attitude and contained many layers of activities. The evidence presented in this LL research is a pattern of human communication through written language.

Based on the description above, this research aims to describe (1) the character education values represented in the text outside the classroom in high school, and (2) strengthening character values for high school students.

\section{METHOD}

This study uses a qualitative approach, namely collecting board of notifications or board containing text, posters, and images found in high schools in Malang with details of 5 schools in Malang city, 2 schools in Malang district, and 3 schools in Batu city. The data are in the form of text taken from posters and boards of notification that are displayed inside the classroom and outside the school environment. Data was collected using observation techniques, and documentation, and field notes. The data were analyzed with the stages of data collection, reduction, classification, analysis, interpretation, and inference.

\section{RESULT AND DISCUSSION}

Based on the results of the analysis, it was found that the values of character education represented in the use of language inside and outside the classroom in schools written on posters and boards of notification which can strengthen students' morale are religious values, protecting the environment, preventing juvenile delinquency, hard work, and love to read. In detail, each character value is described as follows:

\subsection{Motivating religious beliefs}

Religious values are shown by well attitudes and behaviours in carrying out the teachings of their religion, being tolerant of the implementation of worship of other religions, and living in harmony with adherents of others' beliefs. As stated by Ahmad Thontowi (2005) religious value is a form of the human relationship with its creator through religious teachings. It's been internalized and reflected in a person to their daily attitudes and behaviour. The attitude value is found in the text of the boards of notification and posters which are displayed in high/vocational schools in Malang Raya as follows:

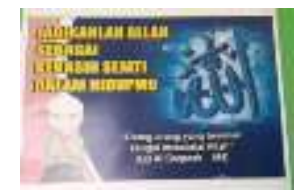

Figure 1

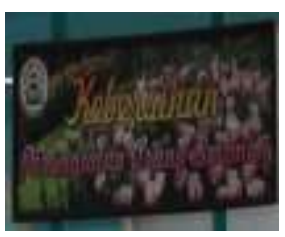

Figure 2

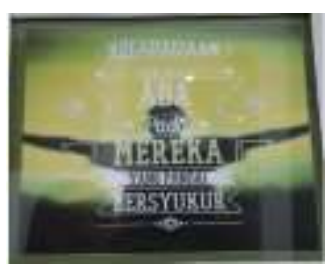

Figure 3

The utterance contained in figure 1 above is "Make God a true lover in your life!". The utterance is in the form of an imperative sentence with the suffix -lah as an emphasis on the command, to make God a true lover in one's life. The value embraced in the speech is advice or an invitation to always run life only to Allah, the God who has created humans. It is confirmed by the expounding of the Word of Allah in QS: AlBaqarah: 165 as an illustration for believers in loving Allah. The utterance in Figure 2 is "Cleanliness of the manifestation of the believer" in the form of a nominal phrase. The message contained in the phrase is about strengthening one's faith by living a clean life behaviour. This can be a suggestion to people always maintain cleanliness. In Figure 3 the utterance is a declarative sentence, 
"Happiness will always be with those who are good at being grateful." The character values contained in the speech are advice or suggestions to humans to always be grateful to be happy in their lives.

\subsection{Maintaining the environment}

Another character value found in the linguistic landscape outside the classroom is caring for the environment. The environment is everything that surrounds humans and affects the development of life. The environment is the combination of physical conditions include the state of natural resources such as soil, water, solar energy, minerals, and flora and fauna that grow on land and in the sea, with institutions that include human creation as a decision how to use the physical environment.

Waste and cleanliness are often the environmental highlighted problem. The threat of waste to the environment is a major problem. Indiscriminate dumping of waste done by the community will cause dreadful consequences and disasters that can harm the community. Many appeals and suggestions have been conveyed either directly or through writings on landscapes, such as the following.

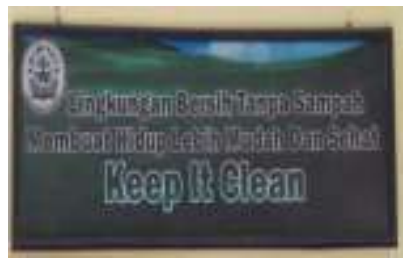

Figure 4

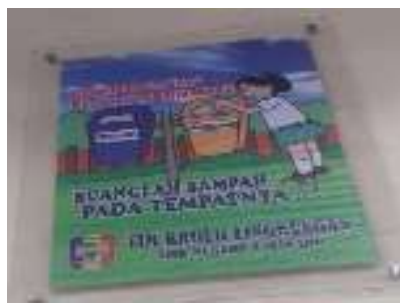

Figure 5

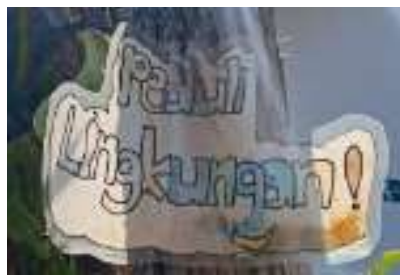

Figure 6

The character of protecting the environment is an attitude and action which continuously tries to prevent damage to the natural environment and develops efforts to repair the damage that has occurred. Based on this concept, the speech in
Figure 4 and Figure 5 appear on a command sentence, and Figure 6 is in the form of a phrase. The character values contained in the speech Figure 4 are an invitation for healthy living by properly cleaning and disposing of waste in its place. The character value in Figure 5 is in the form of an instruction to eliminate the waste in the place provided. The character value in Figure 6 is an invitation to care for environmental awareness. Thus, the characters in the linguistic landscape of Figures 4 and 5 are invitations, while those in Figures 6 are commands.

\subsection{Prevention of juvenile delinquency}

In addition to the character values of protecting the environment, there is preventing juvenile delinquency as in the LL found in the following school environment.

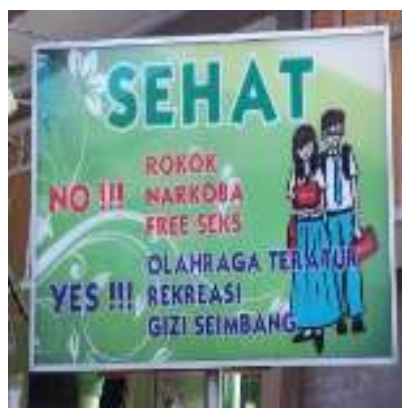

Figure 7

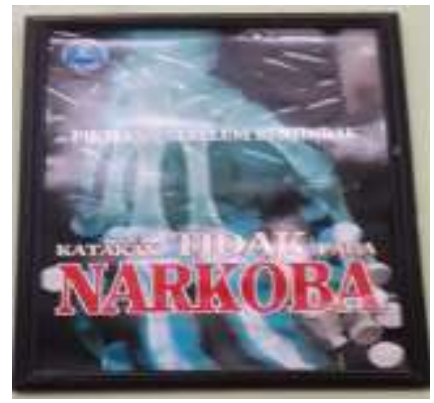

Figure 8

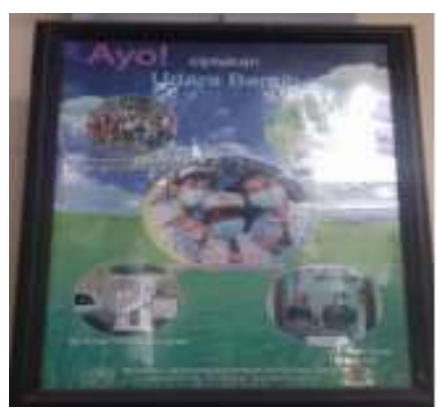

Figure 9

Teenagers are vulnerable to all kinds of outside influences include cigarettes, drugs, and others. Many teenagers drop out of school because they have to serve sentences for being caught taking drugs. Many efforts have been made by the 
government and communities in the form of appeals or counselling. Besides, in the school environment, efforts are made to appeal or invite through boards of notification as in Figures 7, 8, and 9 above. The message contained in Figure 7 is an appeal that is described in declarative form. Figure 8 contains the character preventing from consuming drugs. The utterance in Figure 9 holds an invitation message to create a clean environment.

\subsection{Hard work}

The character of working hard is an activity that is carried out in earnest without getting tired before the work target is reached and always prioritizing or paying attention to the satisfaction of the results in every activity completed. Hard work can be interpreted as having a serious action to achieve goals. The following LL contains the character of hard work.

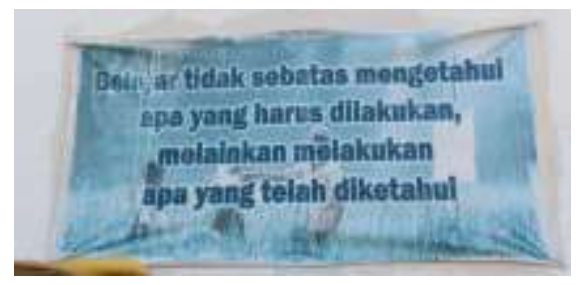

Figure 10

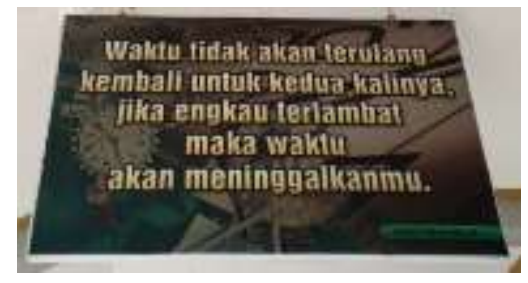

Figure 11

Character values in the linguistic landscape Figure 10 deliver the message that the learning process must be supported by the application of what is learned. Meanwhile, LL figure 11 shows the message that we must make the best use of our time. Work hard to organize and spend time so that what is done is not in vain and wasted. This LL also gives a message that adolescence is a time where self-identity is sought. It should be filled with something useful in selfdevelopment and the future.

\subsection{Bibliophile}

Working hard can also be in the form of cultural education reading books. Reading is an activity of understanding, interpreting, remembering, then the last is rewriting based on the analysis of our thoughts. Besides, reading can also be translated as a kind of creative thinking.
Supposedly, reading has become a culture that runs through our veins. However, reading culture, especially among teenagers, is still shallow. Maybe only a few per cent of teenagers like to read. In this case, the reading material contains knowledge that provides an individual's insight. Most teenagers love to read entertaining books, such as comics, novels, and magazines. Though spending time reading, we will get information and knowledge. No matter how small the knowledge gained, it will be advantageous for us.

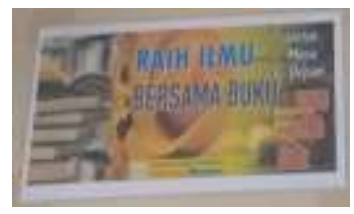

Figure 12

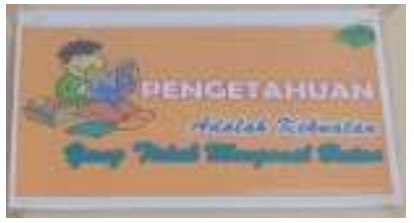

Figure 13

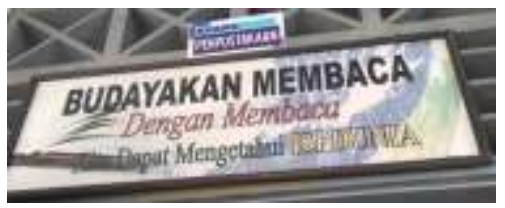

Figure 14

The message contained in figure 12 seeks to promote that science is beneficial for the future. To have a brighter future, books are beneficial yields of knowledge for the future. Knowledge itself is a power that knows no boundaries (figure 13) so reading must be cultivated from now on as illustrated in Figure 14 to gain knowledge to prepare for the future.

\section{CONCLUSION}

Based on the results and discussion, it can be concluded that the character values contained in the LL outside the classroom are the values of religion, protecting the environment, preventing juvenile delinquency, working hard, and liking to read. The presence of LL which contains these character values provides reinforcement and fortifies students' morale, so they do not fall into harmful behaviour. With the number and variety of posters or boards that include utterances containing character values outside the classroom, there will be more information input for students because 
students can read them when they are in and out of school or during their breaks. The display of writing combined with pictures and colours will look attractive to students.

What still needs to be developed in future research is to find various values of character education in the LL displayed outside the classroom that can support the formation of students' character and morals.

\section{REFERENCES}

[1] Cenoz, Jasone \& Durk Gorter. 2006. Linguistic Lanscape and Minority Language. International Journal of Multilinguism.

[2] Spolsky. 2004. Language Policy. New York. Cambridge University Press.

[3] Landry, Rodrigue\&Richard Bourhis.1997. Linguistic Lanscape and Ethnolinguistic Vitality: An Empirical Study. Journal of Language Social and Psichology.

[4] Blommaert. 2013. Ethnography, superdiversity, and Linguistic Lanscape Crhonicles of Complexcity. Bristol: Multilingual Matters. 127 pp.

[5] Taylor, Kerry \&Leech. 2012. Language Choice As an Index of Identity: Linguistic Lanscape in Dili-Timor Leste. International Journal of Multilinguism 